\title{
Effect of surface passivation process for AIGaN/GaN HEMT heterostructures using phenol functionalized-porphyrin based organic molecules
}

Manjari Garg, Tejas Rajendra Naik, Ravi Pathak, Valipe Ramgopal Rao, Che-Hao Liao, Kuang-Hui Li, Haiding Sun, Xiaohang Li, and Rajendra Singh

Citation: Journal of Applied Physics 124, 195702 (2018); doi: 10.1063/1.5049873

View online: https://doi.org/10.1063/1.5049873

View Table of Contents: http://aip.scitation.org/toc/jap/124/19

Published by the American Institute of Physics

\section{Articles you may be interested in}

Dislocations behavior in highly mismatched III-Sb growth and their impact on the fabrication of top-down $n+\ln A s /$ $\mathrm{p}+\mathrm{GaSb}$ nanowire tunneling devices

Journal of Applied Physics 124, 195703 (2018); 10.1063/1.5049900

Temperature dependence of secondary electron emission: A new route to nanoscale temperature measurement using scanning electron microscopy

Journal of Applied Physics 124, 195104 (2018); 10.1063/1.5050250

Significant improvement in the electrical characteristics of Schottky barrier diodes on molecularly modified Gallium Nitride surfaces

Applied Physics Letters 112, 163502 (2018); 10.1063/1.5005587

Evolution of field dependent carrier trapping during off-state degradation for GaN based metal oxide semiconductor high electron mobility transistors

Journal of Applied Physics 124, 165704 (2018); 10.1063/1.5044590

Real-time visualization of GaN/AIGaN high electron mobility transistor failure at off-state Applied Physics Letters 113, 183102 (2018); 10.1063/1.5046178

Identification of the shallow donor state in $\mathrm{Sb}$ doped $\mathrm{ZnO}$ by photoluminescence excitation spectroscopy Journal of Applied Physics 124, 195701 (2018); 10.1063/1.5054337

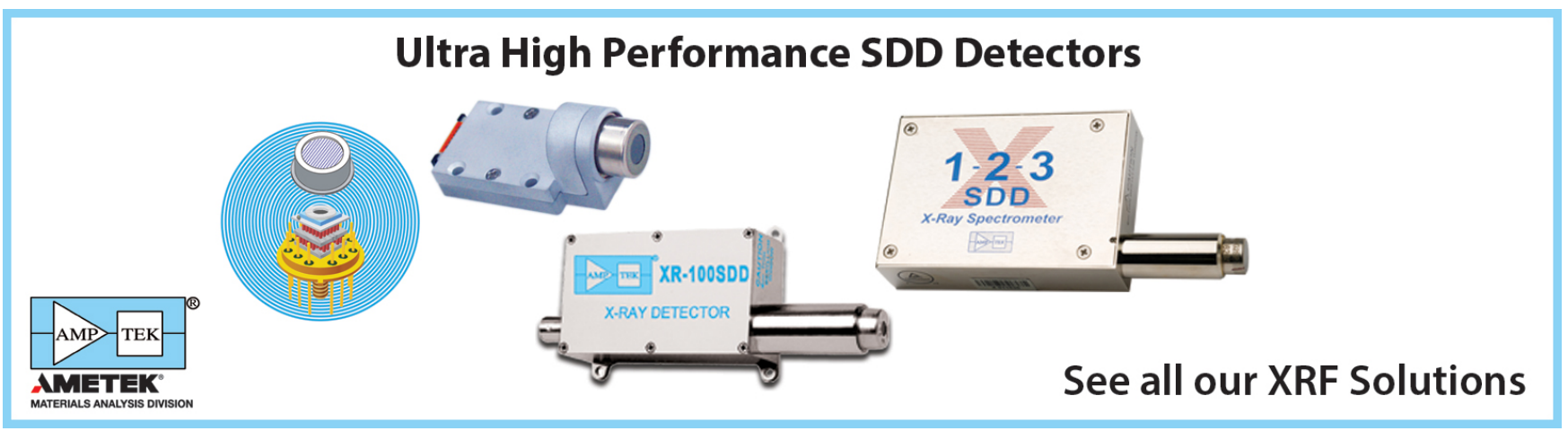




\title{
Effect of surface passivation process for AIGaN/GaN HEMT heterostructures using phenol functionalized-porphyrin based organic molecules
}

\author{
Manjari Garg, ${ }^{1, a)}$ Tejas Rajendra Naik, ${ }^{2}$ Ravi Pathak, ${ }^{1}$ Valipe Ramgopal Rao, ${ }^{3}$ \\ Che-Hao Liao, ${ }^{4}$ Kuang-Hui Li, ${ }^{4}$ Haiding Sun, ${ }^{4}$ Xiaohang Li, ${ }^{4}$ and Rajendra Singh ${ }^{1}$ \\ ${ }^{1}$ Department of Physics, Indian Institute of Technology Delhi, Hauz Khas, New Delhi 110016, India \\ ${ }^{2}$ Centre of Excellence in Nanoelectronics, Indian Institute of Technology Bombay, Powai, Mumbai, \\ Maharashtra 400076, India \\ ${ }^{3}$ Department of Electrical Engineering, Indian Institute of Technology Delhi, Hauz Khas, New Delhi 110016, \\ India \\ ${ }^{4}$ Advanced Semiconductor Laboratory, King Abdullah University of Science and Technology (KAUST), Thuwal \\ 23955-6900, Saudi Arabia
}

(Received 26 July 2018; accepted 30 October 2018; published online 19 November 2018)

\begin{abstract}
In this work, we investigate an unexplored possibility of passivating the charged surface states on AlGaN/GaN high electron mobility transistor (HEMT) heterostructures by using organic molecules. This has further led to remarkable enhancement in the electrical properties of rectifying metal-semiconductor contacts on AlGaN/GaN. Phenol functionalized Zinc metallated-Tetra Phenyl Porphyrin ( $\mathrm{Zn}-\mathrm{TPPOH})$ organic molecules were adsorbed on $\mathrm{AlGaN} / \mathrm{GaN}$ via the solution phase to form a molecular layer $(\mathrm{MoL})$. The presence of the $\mathrm{MoL}$ was confirmed using X-ray Photoelectron Spectroscopy (XPS). The thickness of the MoL was assessed as $\sim 1 \mathrm{~nm}$, using Spectroscopic Ellipsometry and cross-sectional Transmission Electron Microscopy. XPS peak-shift analyses together with Kelvin Probe Force Microscopy revealed that the molecular surface modification reduced the surface potential of $\mathrm{AlGaN}$ by approximately $250 \mathrm{meV}$. Consequently, the Barrier height (ideality factor) of Ni Schottky diodes on $\mathrm{AlGaN} / \mathrm{GaN}$ was increased (reduced) significantly from $0.91 \pm 0.05 \mathrm{eV}(2.5 \pm 0.31)$ for $\mathrm{Ni} / \mathrm{AlGaN} / \mathrm{GaN}$ to $1.37 \pm 0.03 \mathrm{eV}(1.4 \pm 0.29)$ for $\mathrm{Ni} / \mathrm{Zn}$ $\mathrm{TPPOH} / \mathrm{AlGaN} / \mathrm{GaN}$. In addition, a noteworthy decrement in the reverse current from $2.6 \pm 1.93 \mu \mathrm{A}$ to $0.31 \pm 0.19 \mathrm{nA}$ at $-5 \mathrm{~V}(\sim 10000$ times $)$ was observed from Current-Voltage (I-V) measurements. This surface-modification process can be fruitful for improving the performance of $\mathrm{AlGaN} / \mathrm{GaN}$ HEMTs, mitigating the adverse effects of surface states and polarization in these materials. Published by AIP Publishing. https://doi.org/10.1063/1.5049873
\end{abstract}

\section{INTRODUCTION}

The expanding market for cellular, personal communication services, military, or space satellite systems requires radio frequency and microwave power amplifiers. One of the most promising candidates for these technologies is the high electron mobility transistor (HEMT). The potential of HEMTs is a result of its superior device properties and the 2dimensional channel layer which allows the carriers to flow with high mobility. ${ }^{1,2}$ Previous studies from the literature have shown that $\mathrm{AlGaN} / \mathrm{GaN}$ semiconductor materials are ideal for the fabrication of high power, high frequency HEMTs. AlGaN/GaN based HEMTs have been used for various applications such as satellite television receivers, voltage converters, cell phones, high voltage transistor switches, radar equipment, and high power transmitters. ${ }^{3-6}$ This is because along with superior material properties, these heterostructures are characterized by macroscopic polarization (related to high electronegativity of nitrogen) which effectively reduces the on-resistance and thus power loss. ${ }^{7}$ Another unique property of these materials is that no intentional doping is required to generate the two-dimensional

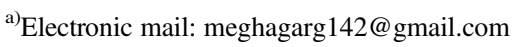

electron gas (2DEG) at the AlGaN/GaN interface. It has been reported that at unintentionally doped strained AlGaN/GaN interface, $2 \mathrm{DEG}$ is formed due to the polarization effect. ${ }^{8,9} \mathrm{It}$ has also been reported that the presence of surface states on AlGaN is another cause for the formation of the 2DEG. ${ }^{10}$ But, on the one hand, surface states are helpful and on the other hand they are responsible for degrading the device performance and reliability. ${ }^{11,12}$

Various sources of surface states have been described, including gap states, ${ }^{13,14}$ defect related states, ${ }^{15}$ and disorder induced gap states (DIGS). ${ }^{16,17}$ A substantial density of these states along with the polarization effect ${ }^{18,19}$ yields a net charge on the surface of the semiconductor which has adverse effects. Firstly, the energy levels of the semiconductor start bending at the surface (either upward or downward depending on the polarity of the surface charge), before forming contact with other materials. Secondly, when the metal comes in contact with the semiconductor, an interface potential is generated at the metal-semiconductor interface leading to Fermi level pinning in the semiconductor and violation of the Schottky-Mott rule $\left(\phi_{\mathrm{Bn}}=\phi_{m}-\chi_{s}\right)^{20-22}$ [where $\phi_{\mathrm{Bn}}$ is the Schottky barrier height $(\mathrm{SBH}), \phi_{m}$ is the work function of the metal, and $\chi_{s}$ is the electron affinity of the semiconductor]. Thirdly, the large concentration of these gap states at the metal/AlGaN/GaN interface also allow 
tunneling of carriers during reverse bias, leading to a large leakage current, ${ }^{12}$ thereby degrading the device efficiency.

In search of strategies to overcome these issues, we came across a unique concept of modulation of the surface electrical properties of some semiconductors by the adsorption of amphiphilic organic molecules. These molecules have a specific structure consisting of three parts: the head group that binds to the substrate (the semiconductor), the tail group that is away from the substrate, and the backbone that connects them..$^{23,24}$ Experimental and theoretical investigations have shown that such an approach reconstructs the surface (onto which the molecules have bonded) and affects the surface energy levels without actual transfer of electrons between the molecule and the substrate. When the molecules are adsorbed onto the surface of the semiconductor, they tune either the surface band-bending ${ }^{25,26}$ (surface potential generated due to the surface charge) of the semiconductor or the electron affinity ${ }^{27,28}$ or sometimes both. ${ }^{29}$ The insertion of the organic molecules at the metalsemiconductor interfaces of Schottky contacts on some semiconductors has also been demonstrated to modify the $\mathrm{SBH}^{30-33}$ and reduce the reverse leakage current, significantly. ${ }^{33}$ Apart from SBH modification, the application of metal/molecular layer/semiconductor structures was also seen when organic molecules of metallated Porphyrin were used as copper metal diffusion barriers for $\mathrm{SiO}_{2}$-Si based CMOS technologies. ${ }^{34}$ Not only the gate electrode, but the application of organic molecules has also been reported to modify the source and drain electrodes on graphene based field-effect transistors. ${ }^{35}$

In this work, the phenomenon of adsorption of the organic molecular layer was applied to AlGaN/GaN HEMT heterostructures to resolve the surface state related issues. The adsorption of different molecules on $\mathrm{AlGaN} / \mathrm{GaN}$ has been reported in the literature. The hybrid organic/AlGaN/GaN interfaces have been used as solution gate field effect transistors for the electronic detection of some specific biomolecular processes. ${ }^{36,37}$ Here, we present, for the first time, the adsorption of phenol functionalized metallated-Tetra Phenyl Porphyrin (Zn-TPPOH) organic molecules on AlGaN/GaN HEMT epitaxial films. The presence of the molecular layer, its bonding with the $\mathrm{AlGaN} / \mathrm{GaN}$ surface, and its thickness were studied using XPS, Spectroscopic ellipsometry, and X-TEM, respectively. XPS peak shift analysis and Kelvin Probe Force Microscopy (KPFM) revealed that the molecular surface-modification was responsible for the decrease in the surface potential of the AlGaN layer. Furthermore, as the Schottky metal was deposited on the molecular-coated $\mathrm{AlGaN} / \mathrm{GaN}$, a considerable increment in the SBH and a noteworthy decrement in the current during the reverse bias were observed from Current-Voltage (I-V) measurements. The working principle of metal/organic molecules/ semiconductor structures has been illustrated with the help of energy band diagrams and schematic illustrations.

\section{EXPERIMENTAL SECTION}

\section{A. Adsorption of the layer of organic molecules}

Organic molecular layers can be adsorbed on the sample surface from either the liquid phase or the vapour phase. ${ }^{23}$ In this work, the molecular layer (MoL) was formed using the solution phase approach where on immersion of the sample in the molecular solution, for some optimized time, the head group of the molecular assemblies spontaneously assemble and bond with the surface atoms of the sample. This is followed by a slow organization of the backbone and the tail part of the molecular assemblies. Due to the specific structure of the molecules (head-backbone-tail assembly) and specialized molecular processing, a single layer of hydrocarbon film (which is selfterminating in nature) is chemisorbed onto the sample surface.

Unintentionally doped $\mathrm{Al}_{0.25} \mathrm{Ga}_{0.75} \mathrm{~N} / \mathrm{GaN}$ high electron mobility transistor (HEMT) epitaxial layers were grown on $2 \mathrm{in}$. diameter c-plane sapphire substrate. The growth was carried out using the Metal-Organic Vapour Phase Epitaxy (MOVPE) technique. The structure of the sample was Sapphire/AIN (nucleation layer $150 \mathrm{~nm}$ ) $/ \mathrm{Al}_{1-\mathrm{x}} \mathrm{Ga}_{\mathrm{x}} \mathrm{N}$ (transition layer $1 \mu \mathrm{m}$ )/UID GaN (channel layer $650 \mathrm{~nm}$ ) $/ \mathrm{Al}_{0.25} \mathrm{Ga}_{0.75} \mathrm{~N}$ (donor layer $25 \mathrm{~nm}$ ), as shown in Fig. 1(a). The Hall effect measurement revealed the room temperature conduction properties of the 2DEG (channel) as Hall electron mobility $\left(\mu_{\mathrm{e}}\right) \sim 1300 \mathrm{~cm}^{2} / \mathrm{Vs}$, sheet carrier concentration $\left(N_{\mathrm{s}}\right) \sim 1.5 \times 10^{13} \mathrm{~cm}^{-2}$, and sheet resistance $\left(R_{\mathrm{s}}\right)$ $\sim 384 \Omega /$ sq. The AlGaN/GaN/Sapphire wafer was diced into pieces of $1 \mathrm{~cm} \times 1 \mathrm{~cm}$ dimension. Thereafter, the sample pieces were cleaned using de-ionized (DI) water, acetone, and isopropanol (IPA), sequentially, in an ultra-sonic bath cleaner for 5 min each at room temperature and again rinsed-off with DI-water. In the next cleaning step, the sample surface was mildly etched by dipping in an acidic solution of hydrochloric acid and water, mixed in the ratio of $1: 2$, for $2 \mathrm{~min}$. The samples were washed with DI-water for a long time, so as to remove the etching remnants. Lastly, the samples were dried properly, using a dry nitrogen jet.

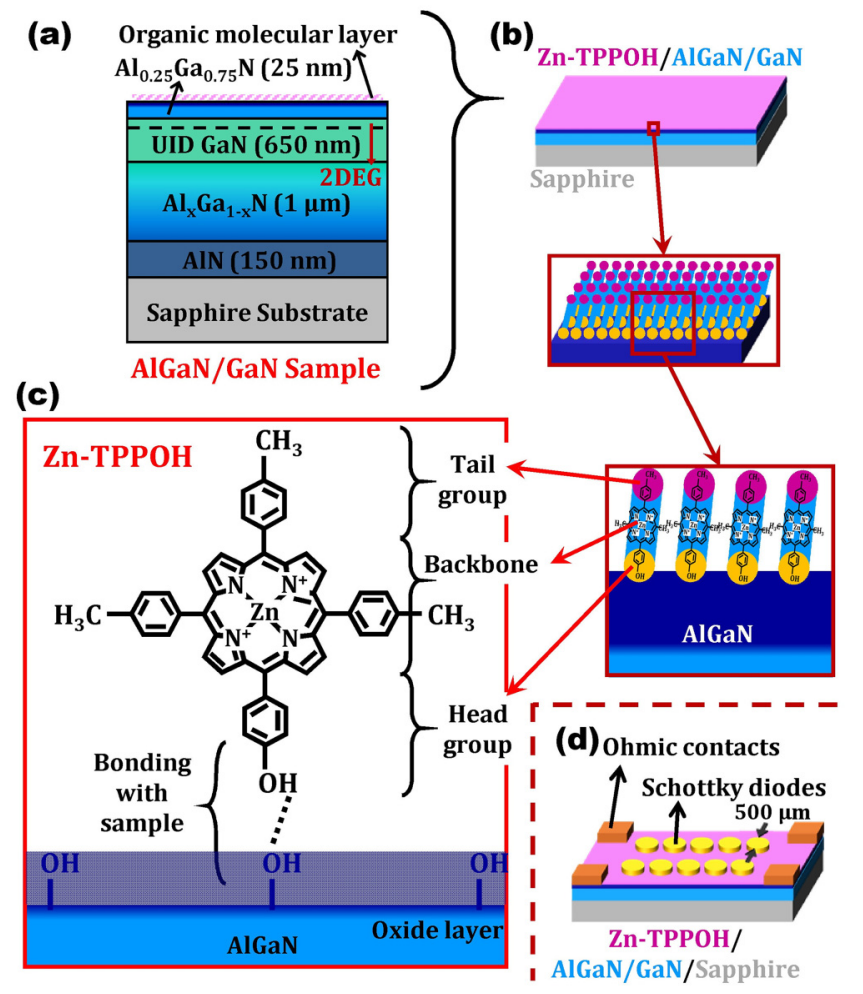

FIG. 1. (a) The structure of the $\mathrm{Al}_{0.25} \mathrm{Ga}_{0.75} \mathrm{~N} / \mathrm{GaN}$ sample. (b) Adsorption of $\mathrm{Zn}$-TPPOH organic molecules on $\mathrm{AlGaN} / \mathrm{GaN}$. (c) Chemical structure of the $\mathrm{Zn}$-TPPOH organic molecule and its bonding with the sample surface. (d) Device structure fabricated on $\mathrm{Zn}-\mathrm{TPPOH} / \mathrm{AlGaN} / \mathrm{GaN}$ samples. 
Hydroxyl-Phenyl-Zinc-Tetra-Phenyl-Porphyrin (Zn-TPPOH) organic molecules were used as the basic precursor for the MoL (preparation explained elsewhere ${ }^{35,38}$ ). The chemical structure of this precursor is shown in Fig. 1(c). These precursor solutes were dissolved in the toluene organic solvent to form a $0.1 \mathrm{mM}$ molecular solution. Following this, some of the cleaned $\mathrm{AlGaN} / \mathrm{GaN}$ samples were placed in the molecular solution for $2 \mathrm{~h}$ (time decided after many optimizations) at room temperature in cleaned air tight bottles (as the toluene solvent is volatile), to get a saturated coverage of the organic molecules on the sample surface, as illustrated in Fig. 1(b). Thereafter, the samples were gently cleaned using iso-propanol and rinsed-off using DI-water. The samples were dried, gently, using the dry nitrogen jet. Furthermore, to remove the moisture, the samples were placed in the hot air oven at $120^{\circ} \mathrm{C}$ for $10-15 \mathrm{~min}$. The $\mathrm{Zn}-\mathrm{TPPOH} / \mathrm{AlGaN} / \mathrm{GaN}$ samples were characterized using X-Ray Photoelectron Spectroscopy [XPS: SPECS; PHOIBOS HSA3500 150 R6 (HW Type 30:14) MCD-9], Variable Angle Spectroscopic Ellipsometry (VASE: J.A. Woollam Inc. Ellipsometry solutions), and Kelvin Probe Force Microscopy (KPFM) (Dimension Icon microscope: Bruker Corporation, Billerica, MA, USA).

\section{B. Device fabrication}

Ohmic contacts were fabricated on the four corners of the cleaned AlGaN/GaN samples. A few Ohmic-contacted samples were dipped in the Zn-TPPOH molecular solution for $2 \mathrm{~h}$ and processed according to the above-mentioned steps. In the next step, Schottky contacts were patterned on both ohmiccontacted bare $\mathrm{AlGaN} / \mathrm{GaN}$ samples and $\mathrm{Zn}-\mathrm{TPPOH} / \mathrm{AlGaN} /$ $\mathrm{GaN}$ in the form of circles having a diameter of $500 \mu \mathrm{m}$ using optical lithography [Intelligent Micro Patterning Maskless Photolithography system (SF-100 Xpress)]. Subsequently, the patterned samples were loaded in the thermal evaporation chamber at a vacuum pressure of $10^{-6}$ Torr. The Nickel (Ni) $(40 \mathrm{~nm}) / \mathrm{Gold}(\mathrm{Au})(100 \mathrm{~nm})$ metal stack was evaporated at a deposition rate of about $1 \AA /$ s. The metal film was finally liftedoff by dipping the samples in hot acetone $\left(100^{\circ} \mathrm{C}\right)$ for $5-10$ min leaving $\mathrm{Ni} / \mathrm{Au}$ metal Schottky contacts on the sample surface. Overall, two different device structures were devised, $\mathrm{Ni} / \mathrm{AlGaN} / \mathrm{GaN}$ and $\mathrm{Ni} / \mathrm{Zn}-\mathrm{TPPOH} / \mathrm{AlGaN} / \mathrm{GaN}$. A schematic representation of the Schottky/MoL/AlGaN/GaN structures is presented in Fig. 1(d). The interfaces of metal/AlGaN/GaN and metal/MoL/AlGaN/GaN structures were imaged using crosssectional Transmission Electron Microscopy (X-TEM: FEI Titan ST microscope system). The current-voltage (I-V) and capacitance-voltage (C-V) characteristics of Schottky contacts on bare $\mathrm{AlGaN} / \mathrm{GaN}$ samples and $\mathrm{MoL}$ coated $\mathrm{AlGaN} / \mathrm{GaN}$ samples were measured using the Keithley Semiconductor Characterization System (SCS-4200).

\section{RESULTS AND DISCUSSION}

\section{A. Characterization of the organic molecular layer on AIGaN/GaN}

\section{X-ray photoelectron spectroscopy (XPS)}

The presence of $\mathrm{Zn}-\mathrm{TPPOH}$ organic molecules on AlGaN/GaN was confirmed by X-Ray Photoelectron
Spectroscopy (XPS). XPS was also used to investigate the nature of bonds formed between the organic molecular layer $(\mathrm{MoL})$ and the c-plane $\mathrm{AlGaN} / \mathrm{GaN}$ surface. XPS measurements were performed with $\mathrm{Al} \mathrm{K} \alpha \mathrm{X}$-ray excitation on $\mathrm{Zn}$-TPPOH coated AlGaN/GaN samples in an ultra-high vacuum $\left(\sim 10^{-9} \mathrm{mbar}\right)$ environment at three different positions on the sample surface. XPS peaks of $\mathrm{Al}, \mathrm{Ga}, \mathrm{N}, \mathrm{O}, \mathrm{C}$, and $\mathrm{Zn}$ elements were deconvoluted using CasaXPS software, after applying Shirley background corrections.

Considering the elements constituting the top layer, $\mathrm{AlGaN}, \mathrm{Al} 2 \mathrm{p}$ scan was fitted by two subpeaks [Fig. 2(a)] which represent Al-N (subpeak 1: $73.69 \pm 0.016 \mathrm{eV})^{39}$ and Al-O (Al-OH) (subpeak 2: $74.45 \pm 0.011 \mathrm{eV})^{39,40}$ bonds. Ga $2 p$ scan was fitted by three subpeaks [Fig. 2(b)] which denote Ga-N (subpeak 3: $1117.34 \pm 0.011 \mathrm{eV}$ ) ${ }^{41}$ bonds, $\mathrm{Ga}-\mathrm{O}(\mathrm{N}-\mathrm{Ga}-\mathrm{OH})$ (subpeak 4: $1118.46 \pm 0.02 \mathrm{eV})^{42}$ bonds, and the Auger peak of $\mathrm{N}$ element (subpeak 5: 1116.12 \pm $0.038 \mathrm{eV}) .{ }^{43} \mathrm{~N} 1 \mathrm{~s}$ scan was fitted by five subpeaks [Fig. 2(c)] depicting N-Al (subpeak 6: $396.87 \pm 0.019 \mathrm{eV})^{39}$ bonds, $\mathrm{N}-\mathrm{Ga}$ (subpeak 8: $397.96 \pm 0.02 \mathrm{eV})^{42}$ bonds, $\mathrm{N}$ element in N-tetraphenylporphyrin (subpeak $7: \quad 397.37 \pm 0.011 \mathrm{eV})^{44}$ (constituent of MoL), and Auger peaks of Ga (subpeak 9: $395.87 \pm 0.029 \mathrm{eV}$ and subpeak 10: $394.62 \pm 0.029 \mathrm{eV})^{45}$ element. These curve fittings confirmed the presence of MoL of porphyrin based organic molecules on the sample surface. Furthermore, the MoL was not bonded to either $\mathrm{Al}, \mathrm{Ga}$, or $\mathrm{N}$ atoms, on the $\mathrm{AlGaN}$ layer.

$\mathrm{C}$ 1s element existed in different species on $\mathrm{Zn}-\mathrm{TPPOH} /$ $\mathrm{AlGaN} / \mathrm{GaN}$, since carbon formed the backbone of the molecular chain. Among them, the following four bonds were prominent and shown in Fig. 2(d), $\mathrm{C}$ 1s in the molecular layer, ${ }^{46} \mathrm{C}-\mathrm{H}$ bonds $\left(\mathrm{CH}_{3}\right),{ }^{47} \mathrm{C}-\mathrm{N}-\mathrm{H}^{46}$ bonds, and $\mathrm{C}-\mathrm{OH}^{46}$ bonds (phenol) designated by subpeaks $11(284.66 \pm 0.017 \mathrm{eV})$, $12(285.16 \pm 0.02 \mathrm{eV}), \quad 13 \quad(285.66 \pm 0.034 \mathrm{eV}), \quad$ and 14 $(286.41 \pm 0.03 \mathrm{eV})$, respectively. This confirmed the presence of MoL of hydroxy-phenyl-porphyrin (TPPOH) organic molecules on the surface of $\mathrm{Zn}-\mathrm{TPPOH} / \mathrm{AlGaN} / \mathrm{GaN}$. The $\mathrm{O} 1 \mathrm{~s}$ spectra were curve fitted by four subpeaks with binding energies: $530.12 \pm 0.031 \mathrm{eV}$ (subpeak 15), $531.12 \pm 0.032 \mathrm{eV}$ (subpeak 16), $531.87 \pm 0.036 \mathrm{eV}$ (subpeak 17), and 532.62 \pm $0.034 \mathrm{eV}$ (subpeak 18), as shown in Fig. 2(e). Subpeak 15 is assigned to $\mathrm{O}$ bonded to $\mathrm{Al}\left[\mathrm{N}-\mathrm{Al}-(\mathrm{OH})_{2}\right]{ }^{39}$ Subpeaks 16 and 18 are attributed to $\mathrm{O}-\mathrm{Ga}(\mathrm{Ga}-\mathrm{OH})^{48}$ bonds and $\mathrm{C}-\mathrm{OH}^{46}$ bonds, respectively. Subpeak 17 is designated to the $\mathrm{OH}$ species (on $\mathrm{AlGaN}$ ) attached to the $\mathrm{OH}$ molecules (phenol) due to hydrogen bonds. ${ }^{48}$ Thus, the MoL of $\mathrm{Zn}-\mathrm{TPPOH}$ was bonded to the hydroxyl layer present on $\mathrm{AlGaN} / \mathrm{GaN}$ via the $\mathrm{OH}$ functionalization, as illustrated in Fig. 1(c). Lastly, the XPS spectra of TPPOH/AlGaN/GaN revealed the presence of the $\mathrm{Zn}$ metal as shown in Fig. 2(f), which was absent in $\mathrm{AlGaN} / \mathrm{GaN}$ [Fig. 2(f), inset figure], thereby confirming the association of the $\mathrm{Zn}$ central metal ion in the TPPOH molecules.

From XPS investigation, it can be said that the organic molecules of phenol functionalized metallated-Tetra Phenyl Porphyrin ( $\mathrm{Zn}-\mathrm{TPPOH})$ followed the concept of selfassembly to form a single layer of the hydrocarbon film, which is self-terminating in nature, on the surface of AlGaN/ $\mathrm{GaN}$. The head group (phenol) was bonded with the sample 

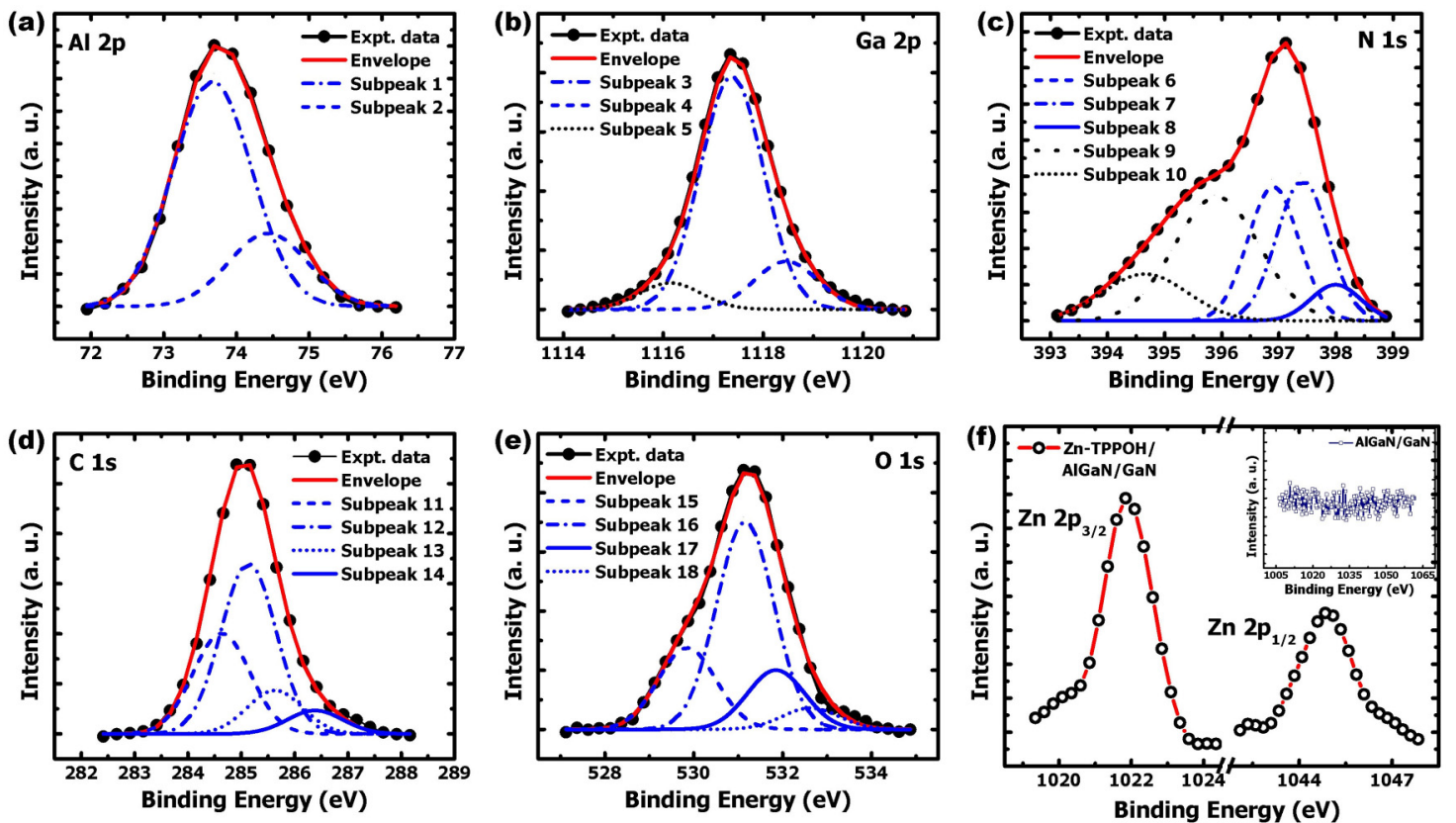

FIG. 2. Deconvoluted XPS peaks of (a) aluminum (Al 2p), (b) gallium (Ga 2p), (c) nitrogen (N 1s), (d) carbon (C 1s), and (e) oxygen (O 1s), elements at the $\mathrm{Zn}-\mathrm{TPPOH} / \mathrm{AlGaN} / \mathrm{GaN}$ sample surface and (f) XPS peaks of zinc ( $\mathrm{Zn} 2 \mathrm{p}$ ), Zn present as the central metal atom in the $\mathrm{Zn}$-TPPOH molecule and absent on bare $\mathrm{AlGaN} / \mathrm{GaN}$ (inset figure).

surface followed by the organization of the backbone and the tail part (Zn-TPP), as illustrated in Figs. 1(b) and 1(c). However, it was not evident whether the molecules were aligned uniformly [as represented in Fig. 1(b)] or not, yet the formation of a single layer of organic molecules was further assessed using Variable angle spectroscopic ellipsometry (which has often been used to determine the thickness of molecular monolayers ${ }^{49-51}$ ) and Cross-sectional Transmission Electron Microscopy (X-TEM).

\section{Variable angle spectroscopic ellipsometry}

Ellipsometric incidence data $\Psi(\lambda)$ were collected at different angles of incidence $\left(50^{\circ}, 55^{\circ}\right.$, and $\left.70^{\circ}\right)$ from bare $\mathrm{AlGaN} / \mathrm{GaN}$ samples and $\mathrm{Zn}-\mathrm{TPPOH} / \mathrm{AlGaN} / \mathrm{GaN}$ samples and analyzed over the transparent region of the samples [where the extinction coefficient $k(\lambda)=0$, from 600 to $900 \mathrm{~nm}$ ]. The experimental data were fitted using the Cauchy dispersion model which is based on the fact that when light of a particular wavelength is incident on a transparent substrate, it refracts, as there is a change of medium. This means that the light deviates from its original path. The amount of deviation is determined by the refractive index. It is also based on the fact that light with a longer wavelength deviates less from its original path, which implies a lesser refractive index, and light with a shorter wavelength deviates more from its path, which implies a higher refractive index. The variation of the refractive index $(n)$ with wavelength $(\lambda)$ is described by Cauchy's equation ${ }^{51,52}$ as

$$
n(\lambda)=A+\frac{B}{\lambda^{2}}+\frac{C}{\lambda^{4}} .
$$

Firstly, the data from $\mathrm{AlGaN} / \mathrm{GaN}$ samples were fitted using a six-layer model consisting of (1) Sapphire substrate, (2) layer 1 (AlN): $150 \mathrm{~nm}$, (3) layer 2 (graded AlGaN): 1000 $\mathrm{nm}$, (4) layer $3(\mathrm{GaN}): 650 \mathrm{~nm}$, (5) layer $4(\mathrm{AlGaN}): 25 \mathrm{~nm}$, and (6) layer 5: a few nanometer thin layer, considered to be the native oxide layer on the AlGaN surface. The plot representing the data fitting is presented in Fig. 3(a). For this fitting, the fitting parameters are tabulated in Table I (S. No. 1).

The thickness of the oxide layer was found to be $3 \pm 0.121 \mathrm{~nm}$. The incorporation of a seventh layer to the above model did not improve the quality of the fits. Next, the data from $\mathrm{Zn}-\mathrm{TPPOH} / \mathrm{AlGaN} / \mathrm{GaN}$ samples were fitted using the model created for the bare sample. But curve-fitting by the exact same model did not give the best fitting. After different iterations, the data were fitted using a seven-layer model consisting of (1) the Sapphire substrate, (2) layer 1 (AlN): $150 \mathrm{~nm}$, (3) layer 2 (graded $\mathrm{AlGaN}$ ): $1000 \mathrm{~nm}$, (4) layer $3(\mathrm{GaN})$ : $650 \mathrm{~nm}$, and (5) layer $4(\mathrm{AlGaN}): 25 \mathrm{~nm}$. Layer 5 (oxide layer) was set to vary around $1 \mathrm{~nm}$ with similar Cauchy constants as charted in Table I for the bare AlGaN/GaN sample (S. No 1). The thickness of layer 5 was obtained as $0.9 \pm 0.052 \mathrm{~nm}$. Layer 6 was added and was set to vary around $1 \mathrm{~nm}$ with slightly different Cauchy constants. The fitting parameters used for this fitting are tabulated in Table I, S. No. 2. Thereby, the thickness of layer 6 , which is regarded as the molecular layer, was approximately $0.9 \pm 0.071 \mathrm{~nm}$. The plot representing the data fitting for $\mathrm{Zn}-\mathrm{TPPOH} / \mathrm{AlGaN} / \mathrm{GaN}$ samples is presented in Fig. 3(b).

\section{Cross-sectional transmission electron microscopy (X-TEM)}

The findings from Spectroscopic Ellipsometry were supported by X-TEM. X-TEM was performed at an acceleration 
(a)

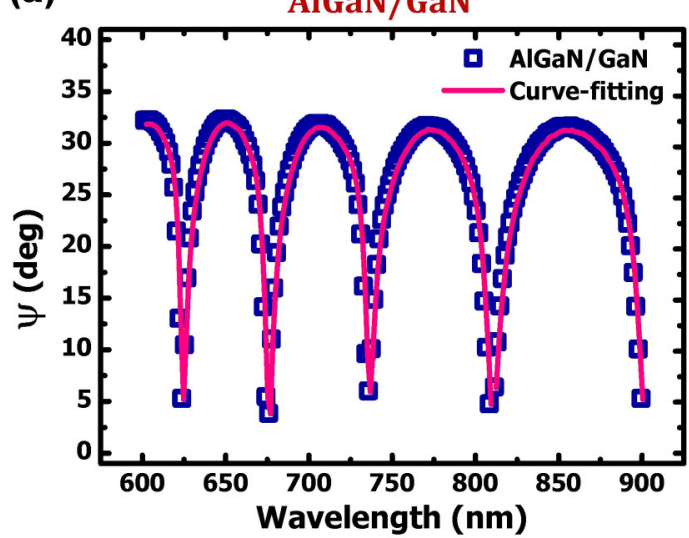

(c)

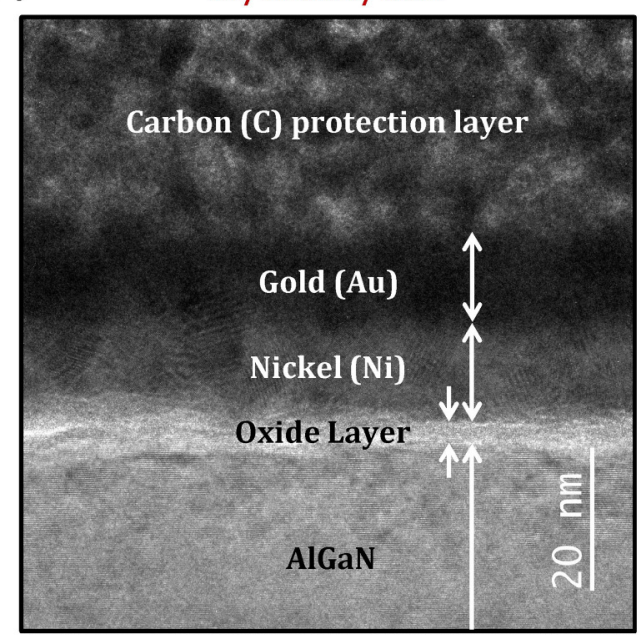

(b)

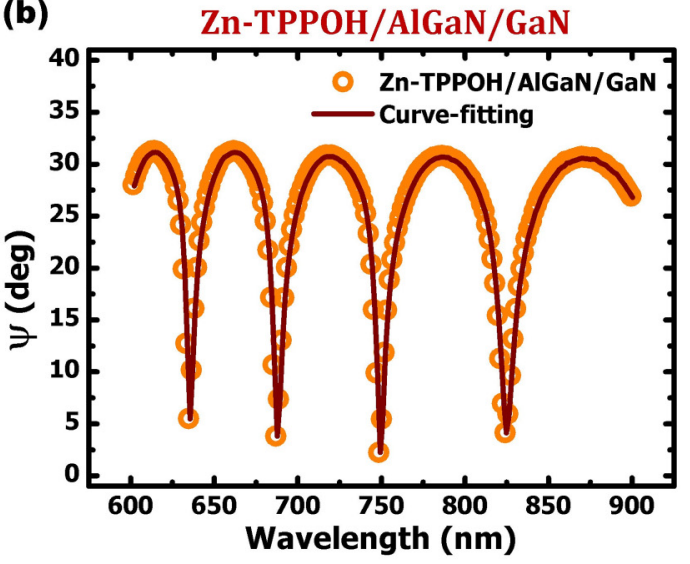

(d)

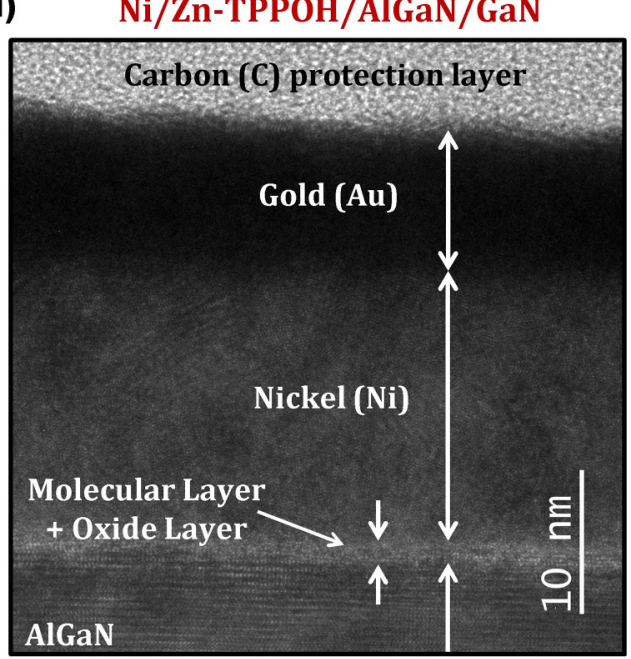

FIG. 3. Spectroscopic ellipsometry showing the variation of $\Psi(\lambda)$ with the wavelength in the transparent region for (a) AlGaN/GaN samples and (b) $\mathrm{Zn}$-TPPOH/AlGaN/GaN samples collected at an incident angle of $50^{\circ}$ and the curve fitting (solid line) using the Cauchy dispersion model; X-TEM images of (c) $\mathrm{Au} / \mathrm{Ni} /$ semiconductor and (d) $\mathrm{Au} / \mathrm{Ni} / \mathrm{MoL} /$ semiconductor structures.

voltage of $300 \mathrm{kV}$ using an FEI Titan ST microscope system. The X-TEM specimens were prepared by focus ion beam (FIB) using an FEI Helios SEM system with a Ga ion source. X-TEM images of $\mathrm{Au} / \mathrm{Ni} / \mathrm{AlGaN} / \mathrm{GaN}$ and $\mathrm{Au} / \mathrm{Ni} /$

TABLE I. Best-fit parameter values from the Cauchy model for AlGaN/ $\mathrm{GaN}$ and $\mathrm{Zn}$-TPPOH/AlGaN/GaN samples.

\begin{tabular}{lccc}
\hline \hline S. No. & Sample & Fitting parameters & Cauchy model \\
\hline 1. & AlGaN/GaN & Mean squared & 28.42 \\
& & error (MSE) & \\
& Thickness (nm) & $3 \pm 0.1211$ \\
& A & $2.28 \pm 0.034$ \\
& B & $0.16 \pm 0.026$ \\
& C & Less influence on data \\
& & fitting, so $\sim 0$ \\
2. & Mean squared & 25.8 \\
& AlGaN/GaN & error (MSE) & \\
& & Thickness (nm) & $0.9 \pm 0.071$ \\
& B & $1.91 \pm 0.057$ \\
& C & $0.10 \pm 0.012$ \\
& & Less influence on data \\
& & fitting, so $\sim 0$ \\
\hline \hline
\end{tabular}

MoL/AlGaN/GaN samples are shown in Figs. 3(c) and 3(d), respectively. Figure 3(c) shows the presence of an amorphous interlayer between $\mathrm{Ni}$ and $\mathrm{AlGaN}$. The thickness of the layer was estimated as $\sim 2.7 \mathrm{~nm}$. This layer was regarded as the oxide layer $^{53}$ that is present at the metal/AlGaN interface. $\mathrm{X}$-TEM on $\mathrm{Ni} / \mathrm{Zn}$-TPPOH/AlGaN/GaN samples showed the presence of another amorphous interlayer having a thickness of $\sim 1.7 \mathrm{~nm}$. This interlayer was related to the combination of the MoL and the oxide layer on AlGaN.

\section{B. Effect of molecular adsorption on the surface electrical properties of AIGaN/GaN}

\section{XPS peak-shift analysis}

After analyzing the presence, the nature of bonding and the quality of the MoL, the effect of adsorption of $\mathrm{Zn}-\mathrm{TPPOH}$ organic molecules was observed on the surface electrical properties of $\mathrm{AlGaN} / \mathrm{GaN}$. Core level XPS peaks of $\mathrm{Al}, \mathrm{Ga}$, and $\mathrm{N}$ surface elements for the $\mathrm{Zn}-\mathrm{TPPOH} / \mathrm{AlGaN} /$ GaN sample was compared to the peak data collected from the bare $\mathrm{AlGaN} / \mathrm{GaN}$ sample surface to analyze the effect. The comparison is shown in Fig. 4, where the upper part of the images relates to deconvoluted XPS peaks for the bare 


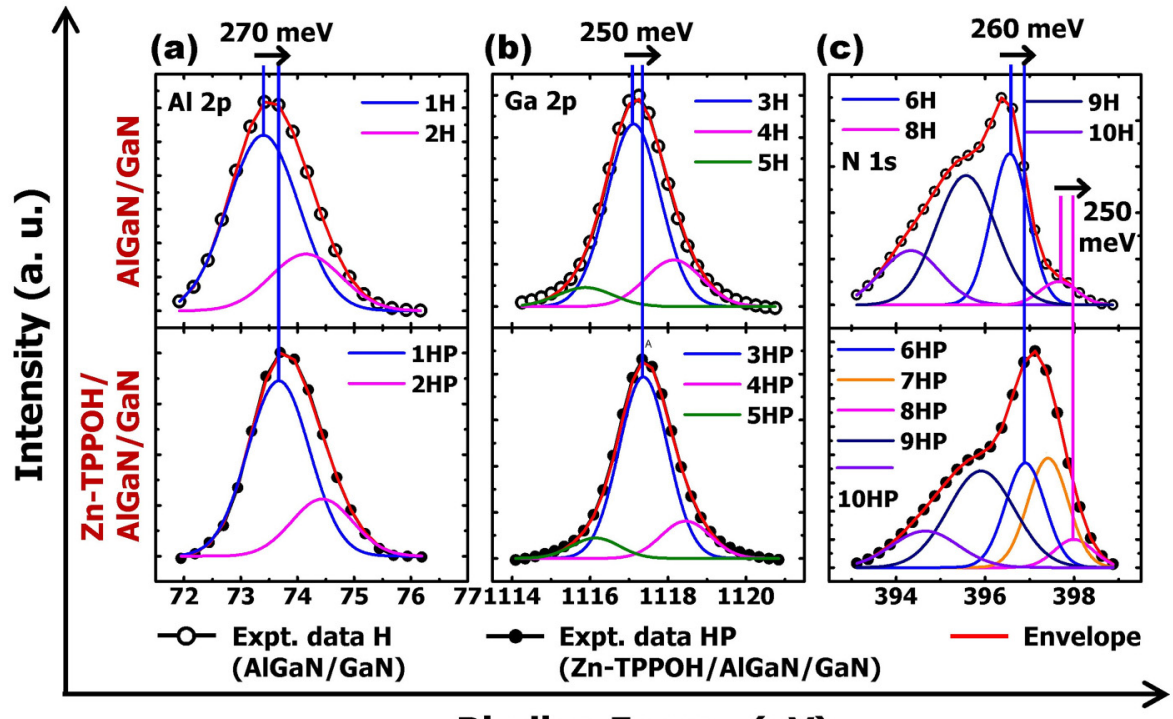

Binding Energy (eV)
FIG. 4. Deconvoluted XPS peaks for (a) Al 2p, (b) Ga 2p, and (c) N 1s elements on $\mathrm{AlGaN} / \mathrm{GaN}$ (upper partdesignated by $\mathrm{H}$ ) and Zn-TPPOH/ AlGaN/GaN (lower part-designated by HP) sample surfaces.
AlGaN/GaN sample, termed as $\mathrm{H}$ in the figure. The lower part of the plots represents the deconvoluted XPS core level peaks for the $\mathrm{Zn}-\mathrm{TPPOH}$-covered $\mathrm{AlGaN} / \mathrm{GaN}$ samples, termed as HP in the figure. It can be seen that there is a shift in the XPS peaks of all the elements toward higher binding energy when the surface of $\mathrm{AlGaN} / \mathrm{GaN}$ is modified by the MoL. XPS signals corresponding to emission from the substrate face an energy difference of approximately $250 \mathrm{meV}$. Subpeak 1H [Fig. 4(a)] representing Al-N bonds was shifted by $\sim 270 \mathrm{meV}$, subpeak $3 \mathrm{H}$ [Fig. 4(b)] representing Ga-N bonds was shifted by $\sim 250 \mathrm{meV}$, and subpeaks $6 \mathrm{H}$ and $8 \mathrm{H}$ [Fig. 4(c)] corresponding to N-Al and N-Ga bonds were shifted by $\sim 260 \mathrm{meV}$ and $\sim 250 \mathrm{meV}$. The Auger peaks of $\mathrm{Ga}$ (subpeaks $9 \mathrm{H}$ and $10 \mathrm{H}$ ) and $\mathrm{N}$ (subpeak $5 \mathrm{H}$ ) elements were also shifted accordingly. The cause of these shifts cannot be attributed to chemical shifts because it has been explained above that the MoL was not bonded to either $\mathrm{Al}$, $\mathrm{Ga}$, or $\mathrm{N}$ elements on the sample surface. Because both the substrates were grounded, this difference in the electrostatic potential at the top of the surface of $\mathrm{AlGaN}$ is attributed to the decrease in the surface potential (surface band- bending $)^{25,26}$ of MoL/AlGaN/GaN samples by approximately $0.25 \mathrm{eV}$.

\section{Kelvin probe force microscopy (KPFM)}

Kelvin Probe Force Microscopy (KPFM) was employed as the secondary method to compare the change in the surface potential of $\mathrm{AlGaN} / \mathrm{GaN}$ due to the surface alteration by the MoL adsorption. KPFM was used considering the fact that the contact potential difference (CPD) (measured by KPFM) is related to the surface potential for a semiconductor surface (due to the space charge layer). ${ }^{12,54,55}$ KPFM was performed in air on both $\mathrm{AlGaN} / \mathrm{GaN}$ and MoL/AlGaN/GaN samples. Prior to the measurements, the probe tip was calibrated with respect to freshly cleaved highly oriented pyrolytic graphite (HOPG), used as a reference material. The same tip was then used for measuring the contact potential difference at five different locations on both bare cleaned AlGaN/GaN samples and MoL bonded AlGaN/GaN samples at a scan size of $10 \times 10 \mu \mathrm{m}^{2}$. The values of the potential were calculated by Nanoscope Analysis software, and the

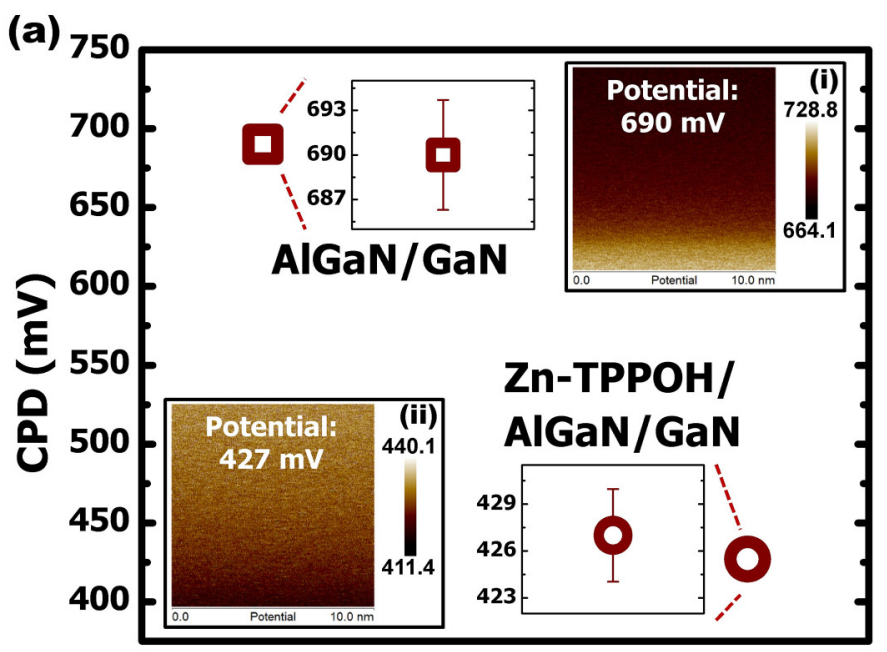

(b)

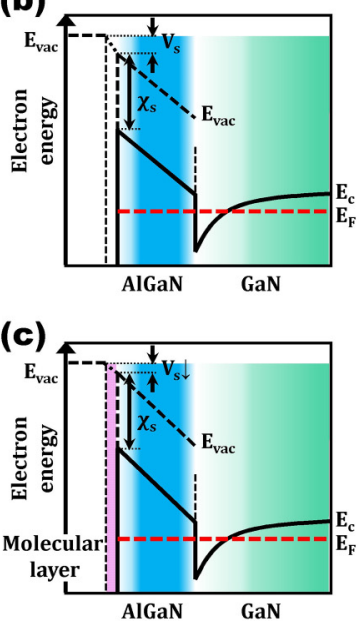

FIG. 5. (a) Plot showing values of CPD (with error bars in the inset) for $\mathrm{AlGaN} / \mathrm{GaN}$ and $\mathrm{Zn}-\mathrm{TPPOH} / \mathrm{AlGaN} /$ GaN samples; inset KPFM image of (i) $\mathrm{AlGaN} / \mathrm{GaN}$ and (ii) $\mathrm{Zn}-\mathrm{TPPOH} /$ AlGaN/GaN samples. The conduction energy band diagram for (b) bare $\mathrm{AlGaN} / \mathrm{GaN}$, and (c) Zn-TPPOH/ $\mathrm{AlGaN} / \mathrm{GaN}$ showing a decrease in the surface potential due to the adsorption of MoL. 
KPFM images are shown in the inset of Fig. 5(a) (i and ii). The value of the CPD was found to be $690 \pm 4 \mathrm{mV}$ for bare cleaned the $\mathrm{AlGaN} / \mathrm{GaN}$ sample surface. It was observed that CPD decreased to $427 \pm 3 \mathrm{mV}$ when MoL of $\mathrm{Zn}-\mathrm{TPPOH}$ organic molecules was chemisorbed on the sample surface, as plotted in Fig. 5(a). These measurements revealed that the adsorption of the organic molecular monolayer was responsible for the considerable reduction in the surface potential of $\mathrm{AlGaN} / \mathrm{GaN}$ by $\sim 260 \mathrm{meV}$. It can also be seen that this value is similar to the values obtained from the shift in the XPS peak (toward higher binding energy) of the substrate elements $\mathrm{Al}, \mathrm{Ga}$, and $\mathrm{N}$ by $\sim 0.25 \mathrm{eV}$, as presented above.

\section{Effect of molecular surface passivation on electrical properties of device structures}

\section{Current-voltage (I-V) measurements}

This part demonstrates the application of adsorption of organic molecules for improving the electrical characteristics of nickel Schottky diodes on AlGaN/GaN. Current-Voltage (I-V) characteristics of two device structures were measured and compared, $\mathrm{Ni} / \mathrm{AlGaN} / \mathrm{GaN}$ and $\mathrm{Ni} / \mathrm{Zn}-\mathrm{TPPOH} \mathrm{MoL} /$ AlGaN/GaN Schottky barrier diodes (SBDs). I-V was measured using tungsten $(\mathrm{W})$ needles with a tip diameter of 50 $\mu \mathrm{m}$, connected to micromanipulators in EverBeing DC Probe station (EB 6) and the Keithley SCS-4200 semiconductor characterization system, in a voltage sweep mode. One probe was connected to the Ohmic contact, and the other was gently touched onto the Schottky diodes. The measurements were taken on ten SBDs on each sample, at room temperature. A schematic representation of the electrical characterization is drawn in the inset of Fig. 6(b). I-V curves in the log scale, comparing the electrical characteristics of Ni SBDs on bare AlGaN/GaN samples and Zn-TPPOH/AlGaN/GaN samples in both forward and reverse bias, are shown in Fig. 6(a). A noteworthy decrement in the current during the reverse bias is manifested when the MoL of phenol functionalized organic molecules was inserted between the metal and the semiconductor. The current was reduced by up to $\sim 4$ orders of magnitude (from $2.6 \pm 1.93 \mu \mathrm{A}$ to $0.31 \pm 0.198 \mathrm{nA}$ ) at $-5 \mathrm{~V}$. For clarity, the error bar in reverse current [Fig. 6(a)] is presented for each curve at only one negative bias voltage. In the forward bias, the Schottky barrier height was calculated using the thermionic emission current equation. For thermionic emission (TE) and for $V>3 k T / q$, the general diode equation is given by ${ }^{56}$

$$
I_{n}=\left[A A^{*} T^{2} \exp \left(-\frac{q \phi_{\mathrm{BnTE}}}{k T}\right)\right]\left[\exp \left(\frac{q V}{\eta k T}\right)-1\right]
$$

where $A$ is the area of the Schottky diode, $A^{*}$ is the effective Richardson coefficient, $T$ is the absolute temperature, $q$ is the fundamental electronic charge, $\phi_{\mathrm{BnTE}}$ is the barrier height, $k$ is Boltzmann's constant, $V$ is the applied voltage, and $\eta$ is the ideality factor. Taking the ln of Eq. (2), the Schottky
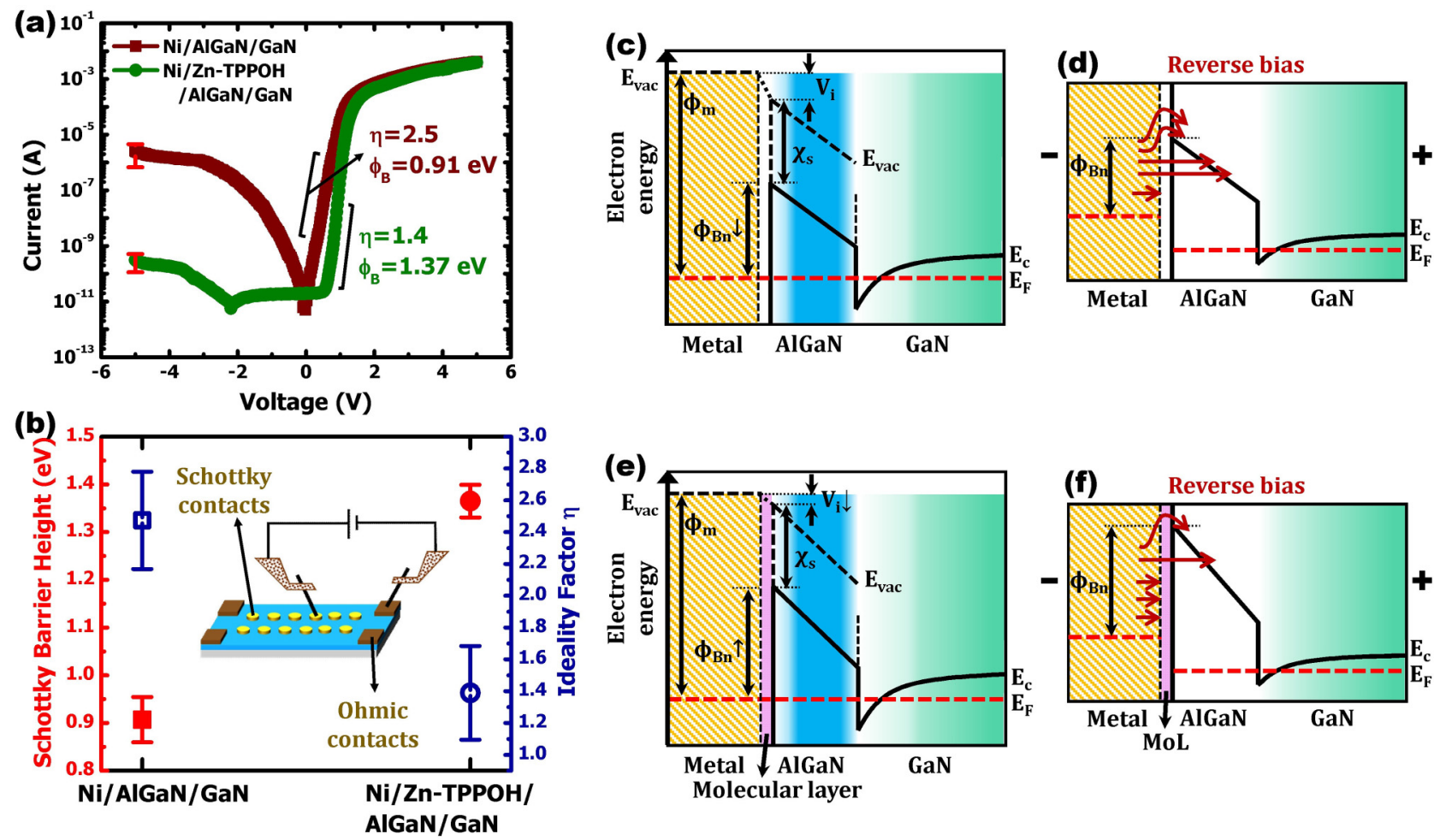

FIG. 6. (a) I-V characteristics comparing the electrical characteristics of Ni/AlGaN/GaN (square icon) and Ni/Zn-TPPOH MoL/AlGaN/GaN (circle icon) SBDs; (b) Plot showing the significant improvement in the calculated values of IF (blue colour) and SBH (red colour) for Ni/Zn-TPPOH/AlGaN/GaN SBDs (circle shaped icons) as compared to Ni/AlGaN/GaN SBDs (square shaped icons), measurement done on 10 SBDs on each sample; inset figure: A schematic illustration of electrical characterization of Ni SBDs on AlGaN/GaN samples; Conduction energy band diagram for (c) metal/AlGaN/GaN structures (d) reverse biased metal/AlGaN/GaN (e) metal/MoL/AlGaN/GaN structures, and (f) reverse biased metal/MoL/AlGaN/GaN. 
barrier height $(\mathrm{SBH})$ was calculated using the relation

$$
\phi_{\mathrm{bo}}=\frac{k T}{q} \ln \left(\frac{A A^{*} T^{2}}{I_{s}}\right),
$$

where $I_{S}$ is the saturation current which is calculated from the $\mathrm{y}$ axis intercept of the $\ln \mathrm{I}-\mathrm{V}$ plot. $\mathrm{SBH}$ was calculated as $0.91 \pm 0.05 \mathrm{eV}$ for $\mathrm{Ni} \mathrm{SBD}$ on $\mathrm{AlGaN} / \mathrm{GaN}$. It was seen that $\mathrm{SBH}$ was increased to $1.37 \pm 0.03 \mathrm{eV}$ for $\mathrm{Ni}$ SBDs on Zn-TPPOH MoL/AlGaN/GaN samples [shown in Fig. 6(b)]. Ideality factor (IF) $(\eta)$, which was calculated using the relation $\eta=\frac{q}{k T}\left(\frac{d V}{d(\ln I)}\right)$, was found to decrease from $2.5 \pm$ 0.31 for $\mathrm{Ni} / \mathrm{AlGaN} / \mathrm{GaN} \mathrm{SBDs}$ to $1.4 \pm 0.29$ for $\mathrm{Ni} /$ Zn-TPPOH/AlGaN/GaN SBDs [shown in Fig. 6(b)]. A noticeable improvement in the $\mathrm{SBH}$ was observed due to chemisorption of phenol functionalized TPP organic molecules on $\mathrm{AlGaN} / \mathrm{GaN}$ samples.

\section{Capacitance-voltage (C-V) measurements}

Capacitance-Voltage $(\mathrm{C}-\mathrm{V})$ profiling was done to get information about the effect of molecular surface passivation on the sheet carrier concentration of the 2-dimensional channel layer at the AlGaN/GaN interface. $\mathrm{C}-\mathrm{V}$ measurements were done using the same DC probe station and the semiconductor characterization system as was used for I-V measurements. One probe was connected to the Ohmic contact, and the other was gently touched onto the Schottky diodes, as illustrated in the inset of Fig. 6(b). The system was operated at room temperature in the voltage sweep mode at a frequency of $10 \mathrm{KHz}$. The experimentally obtained values of capacitance as a function of voltage for Ni/AlGaN/GaN and $\mathrm{Ni} / \mathrm{Zn}-\mathrm{TPPOH} / \mathrm{AlGaN} / \mathrm{GaN}$ Schottky structures are plotted in Fig. 7(a). It can be seen that there is a hump at around $-4 \mathrm{~V}$ in the $\mathrm{C}-\mathrm{V}$ curve of $\mathrm{Ni} / \mathrm{AlGaN} / \mathrm{GaN}$ Schottky diodes. This is indicative of the presence of interface trap states due to the oxide interlayer (native oxide layer) at the metalsemiconductor interface. ${ }^{57}$ Furthermore, the hump is reduced for $\mathrm{Ni} / \mathrm{Zn}-\mathrm{TPPOH} / \mathrm{AlGaN} / \mathrm{GaN}$ Schottky structures. This reveals a decrease in the density of interface states at the metal/MoL/semiconductor interface. It can also be seen that there is a decrease in the capacitance in the region where the channel is fully open, when the surface of AlGaN/GaN is coated with the MoL, as elaborated in the inset of Fig. 7(a). From C-V profiling, the carrier concentration can be calculated using the mathematical expression, ${ }^{58}$

$$
N_{\mathrm{C}-\mathrm{V}}=\frac{C^{3}}{e \epsilon \epsilon_{o}} \frac{d V}{d C}
$$

as a function of depth which is given by

$$
z_{\mathrm{C}-\mathrm{V}}=\frac{\epsilon \epsilon_{o}}{C},
$$

where $C$ is the measured differential capacitance per unit area, $V$ is the voltage applied to the Schottky contact, $\epsilon$ is the dielectric constant of the material, $\epsilon_{o}$ is the dielectric constant of air, and $e$ is the electronic charge. The calculated $N_{\mathrm{C}-\mathrm{V}}\left(z_{\mathrm{C}-\mathrm{V}}\right)$ profiles for $\mathrm{AlGaN} / \mathrm{GaN}$ and $\mathrm{Zn}-\mathrm{TPPOH} /$ $\mathrm{AlGaN} / \mathrm{GaN}$ samples are shown in Fig. 7(b). It can be seen that firstly, the carrier concentration is the highest at the depth where the $\mathrm{AlGaN} / \mathrm{GaN}$ interface lies, indicating the formation of $2 \mathrm{DEG}$ for both the samples. Secondly, the carrier concentration of the 2DEG for the $\mathrm{Zn}-\mathrm{TPPOH} /$ AlGaN/GaN samples was reduced as compared to that obtained for bare $\mathrm{AlGaN} / \mathrm{GaN}$ samples. In order to find the values of the sheet carrier concentration in the channel, $N_{\mathrm{C}-\mathrm{V}}$ was integrated with respect to $z_{\mathrm{C}-\mathrm{V}}$ using the equation, ${ }^{58}$

$$
n_{s}=\int_{-\infty}^{\infty} N_{\mathrm{C}-\mathrm{V}}\left(z_{\mathrm{C}-\mathrm{V}}\right) \mathrm{d} z_{\mathrm{C}-\mathrm{V}}=\int_{-\infty}^{\infty} n(z) d z .
$$

The value of sheet concentration in the 2-dimensional channel layer was calculated as $1.09 \times 10^{13} \mathrm{~cm}^{-2}$ for bare AlGaN/GaN. $n_{s}$ was decreased to $9.4 \times 10^{12} \mathrm{~cm}^{-2}$ for Zn-TPPOH/AlGaN/GaN samples. Thus, due to the adsorption of organic molecules on $\mathrm{AlGaN} / \mathrm{GaN}$, the sheet carrier concentration was decreased, though slightly.

\section{Discussion}

AlGaN/GaN HEMTs are specialized because of the presence of the 2-dimensional channel layer termed as the 2dimensional electron gas (2DEG) which allows the carriers to flow with higher mobility. For n-doped AlGaN or GaN layers, the $2 \mathrm{DEG}$ is formed by the concept of modulation doping. ${ }^{59}$ On the other hand, for undoped epilayers, the mechanism is different. In some reports, it is demonstrated that $2 \mathrm{DEG}$ for undoped $\mathrm{AlGaN}$ layers is formed due to the effect of polarization in III-Nitride semiconducting materials. ${ }^{58}$ In other reports, the experimentally observed higher electron density in 2DEG has been explained by demonstrating the existence of donor-like states on the surface of
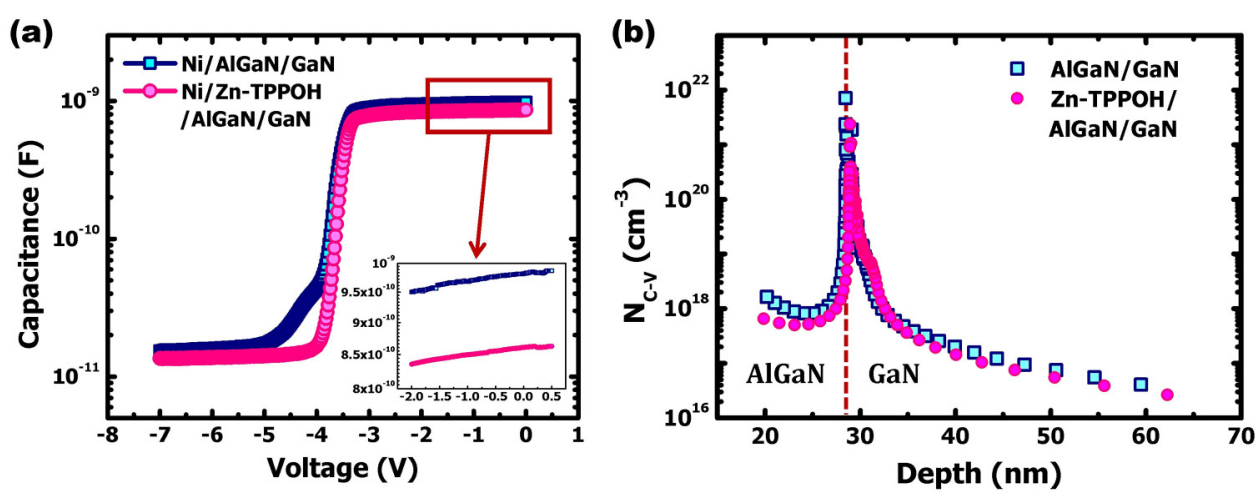

FIG. 7. (a) $\mathrm{C}-\mathrm{V}$ characteristics for $\mathrm{Ni} /$ $\mathrm{AlGaN} / \mathrm{GaN}$ and $\mathrm{Ni} / \mathrm{Zn}-\mathrm{TPPOH} /$ $\mathrm{AlGaN} / \mathrm{GaN}$ Schottky structures at a frequency of $10 \mathrm{KHz}$ (b) $\mathrm{C}-\mathrm{V}$ concentration profile $\mathrm{N}_{\mathrm{C}-\mathrm{V}} V s$ penetration depth for $\mathrm{AlGaN} / \mathrm{GaN}$ and $\mathrm{Zn}-\mathrm{TPPOH} /$ $\mathrm{AlGaN} / \mathrm{GaN}$ structures. 
(a)

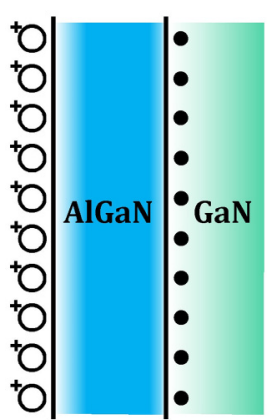

(c) MoL

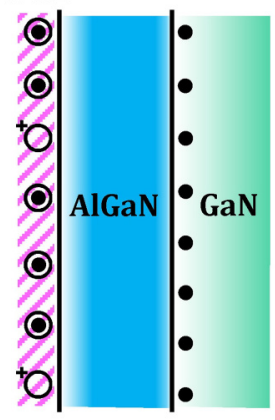

(b)

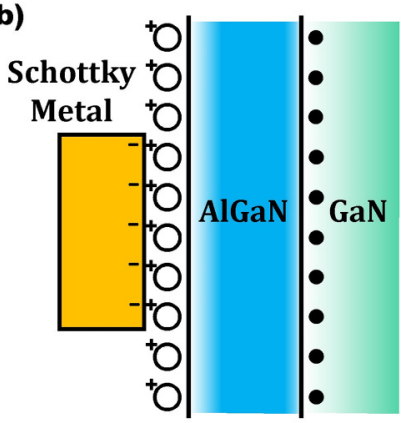

(d)

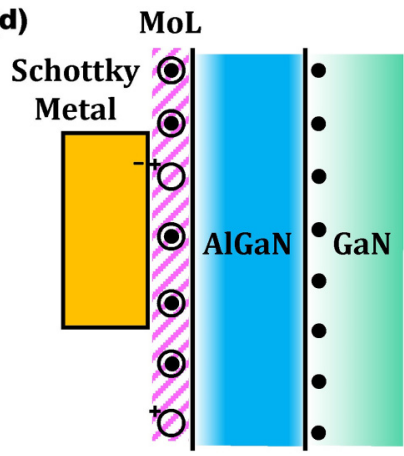

FIG. 8. Schematic illustration for distribution of charge carriers for (a) bare AlGaN/GaN, (b) metal/AlGaN/GaN, (c) MoL/AlGaN/GaN, and (d) metal/ $\mathrm{MoL} / \mathrm{AlGaN} / \mathrm{GaN}$ structures.

$\mathrm{AlGaN}^{10}$ (originating from either native oxide layer or structural defects or unsatisfied bonds on the surface). ${ }^{60}$ It may be noted that surface states are termed as donor-like in the sense that they are neutral when occupied by electron and positively charged when they are empty. It has been shown that for a certain critical thickness of the AlGaN layer, the electrons are transferred from the occupied surface states to the empty conduction band states at the interface, thereby creating the 2 DEG. ${ }^{10}$ However, despite the benefits of these mechanisms (in forming the 2DEG for undoped epilayers), there are certain issues that hinder a good device performance. One of the major issues is the formation of positive surface charge due to both the mechanisms. ${ }^{10,18}$ The surface charge leads to band-bending at the surface of the semiconductor, the extent of which is described by the surface potential $^{61}$ ( $\sim 690 \mathrm{meV}$ for our case). The presence of the surface potential and the formation of 2DEG are illustrated in the form energy band diagram in Fig. 5(b) and in the form of schematic illustration in Fig. 8(a). ${ }^{62}$

When the Schottky metal is deposited on the AlGaN/ $\mathrm{GaN}$ heterostructure, the parasitic charge on the surface of the semiconductor forms an image charge on the surface of metal leading to the formation of interface dipoles, as illustrated in Fig. 8(b). ${ }^{20}$ This further leads to the formation of interface potential $V_{i}$, as illustrated in Fig. 6(c). This interface potential adversely affects the Schottky barrier $\left(\phi_{\mathrm{Bn}}\right)$ formed at the metal-semiconductor interface, according to the equation $^{20}$

$$
\phi_{\mathrm{Bn}}=\phi_{m}-\chi_{s}-V_{i},
$$

where $\phi_{m}$ is the work function of the metal and $\chi_{s}$ is the

electron affinity of the semiconductor. It can be seen from Eq. (7) that as $V_{i}$ increases, $\phi_{\mathrm{Bn}}$ decreases $\left(\phi_{\mathrm{Bn}-\mathrm{Ni} / \mathrm{AlGaN} / \mathrm{GaN}} \sim 0.91 \mathrm{eV}\right)$. When such a metalsemiconductor structure is given a reverse bias, then as the carriers move from the metal to the semiconductor, firstly, they find a free trap state pathway (due to surface states), which allows tunneling of the carriers. Secondly, they also face a lower potential barrier at the interface and tend to jump over the barrier to reach the semiconductor side, as shown in Fig. 6(d), thereby leading to a higher reverse bias leakage current (in $\sim \mu \mathrm{A}$ range for our case).

In this work, the solution to the issues due to surface states is sought by the adsorption of a single layer of organic molecules. From experimental observations, it is evident that by the adsorption of the molecular layer $(\mathrm{MoL})$, the surface potential on $\mathrm{AlGaN} / \mathrm{GaN}$ is reduced, as illustrated in the form of the energy band diagram in Fig. 5(c). Shifting of XPS peaks of substrate elements toward higher binding energies and KPFM images revealed a decrease in the surface potential of molecular-coated $\mathrm{AlGaN} / \mathrm{GaN}$ by $\sim 250 \mathrm{meV}$. The decrease in the surface potential is indicative of the decrease in the surface charge which is attributed to different reasons. Firstly, the organic molecular adsorption process has led to a decrease in the density of surface states, as illustrated in Fig. 8(c). This is because the thinner oxide layer was detected in X-TEM images of $\mathrm{Zn}-\mathrm{TPPOH} / \mathrm{AlGaN} /$ $\mathrm{GaN}$ samples and the hump at $-4 \mathrm{~V}$ in the $\mathrm{C}-\mathrm{V}$ measurements was reduced for $\mathrm{Ni} / \mathrm{Zn}-\mathrm{TPPOH} / \mathrm{AlGaN} / \mathrm{GaN}$ structures. Secondly, there is some molecule-semiconductor interaction (interaction between the electric field generated by the dipoles of organic molecules and the surface charge $^{63,64}$ or some induction of charges ${ }^{65}$ ) due to which the 2DEG electrons are extracted to the void surface donor-like surface states, thereby reducing the surface charge (by making them neutral), as represented in Fig. 8(c). This can be said because the carrier concentration of the 2DEG was found to be reduced for MoL/AlGaN/GaN samples. However, at this point, we are unable to explain the exact mechanism at the molecule-semiconductor interface.

When the metal comes in contact with the MoL/AlGaN/ $\mathrm{GaN}$ surface, lesser surface charge is left between the metal and the MoL/AlGaN/GaN surface, as illustrated in Fig. 8(d), leading to a decrease in the interface potential $V_{i}$, as shown in Fig. 6(e). As a consequence, the Schottky barrier height is increased $\left(\phi_{\mathrm{Bn}-\mathrm{Ni} / \mathrm{Zn}-\mathrm{TPPOH} / \mathrm{AlGaN} / \mathrm{GaN}} \sim 1.37 \mathrm{eV}\right)$, according to Eq. (7). When the metal/MoL/semiconductor structure is given reverse bias, then the carriers moving from the metal to the semiconductor face a blocked trap state pathway, thereby reducing tunneling at the metalsemiconductor interface. As the carriers tend to jump over the barrier to reach the semiconductor side, they face an increased potential barrier, as presented in Fig. 6(f). Accordingly, the experimentally observed reverse bias leakage current for $\mathrm{Ni} / \mathrm{Zn}-\mathrm{TPPOH} / \mathrm{AlGaN} / \mathrm{GaN}$ structures was reduced by $\sim 3-4$ orders of magnitude to $\mathrm{nA}$ range. Conclusively, the passivation of surface states has led to enhancement in the device performance (lower reverse current implies better functioning of the gate electrode and a higher device breakdown voltage). 


\section{CONCLUSIONS}

In summary, organic molecules of phenol functionalized metallated-Tetra Phenyl Porphyrin were adsorbed on AlGaN/ GaN HEMT heterostructures. The organic molecules followed the concept of self-assembly, as assessed from $\mathrm{XPS}$, to form a monolayer on $\mathrm{AlGaN} / \mathrm{GaN}$, as estimated from Ellipsometry and X-TEM. The effect of molecular surface assimilation was seen in the form of a decrease in the surface potential on $\mathrm{AlGaN} / \mathrm{GaN}$ by $\sim 250 \mathrm{meV}$, as revealed by XPS peak-shift analyses and KPFM. Consequently, the electrical characteristics of rectifying metal-semiconductor contacts on $\mathrm{Zn}-\mathrm{TPPOH} / \mathrm{AlGaN} / \mathrm{GaN}$ were significantly enhanced. This was because the molecular layer was passivating the donor-like surface states on $\mathrm{AlGaN} / \mathrm{GaN}$ by either extracting the charge carriers from the 2DEG, as evident from capacitance-voltage measurements, or by reducing the density of surface states (oxide layer-related states), as evident from X-TEM. These analyses signify that the implementation of the innovative concept of organic molecular layer insertion (at the metal-semiconductor interface) opens up a viable and inexpensive pathway for enhancing the device performance and reliability of $\mathrm{AlGaN} / \mathrm{GaN}$ based high electron mobility transistors, mitigating the adverse effects of surface states and polarization in these materials.

\section{ACKNOWLEDGMENTS}

Manjari Garg is grateful to the Council of Scientific and Industrial Research (CSIR), India, for providing research fellowship. The authors would like to acknowledge Indian Nanoelectronics User Program (INUP) at Indian Institute of Technology Bombay for the molecular chemisorption work and XPS measurements. The authors are also thankful to Professor M. Ravikanth, IIT Bombay, for porphyrin based organic molecules. The authors are also obliged to Nanoscale Research Facility (NRF) at Indian Institute of Technology Delhi for the deposition of $\mathrm{Cu}$ and $\mathrm{Ni}$ Schottky contacts and for KPFM, Spectroscopic Ellipsometry, and I-V and C-V measurements. The KAUST authors acknowledge the support from KAUST Baseline BAS/1/1664-01-01, KAUST Competitive Research Grant URF/1/3437-01-01, and GCC Grant REP/1/3189-01-01.

${ }^{1}$ T. Mimura, IEEE Trans. Microw. Theory Tech. 50, 780 (2002).

${ }^{2}$ O. Hammi and F. M. Ghannouchi, in Proceedings of the 16th IEEE International Conference on Electronics, Circuits and Systems (ICECS) (IEEE, Yasmine Hammamet, 2009), p. 379.

${ }^{3}$ T. Oka and T. Nozawa, IEEE Electron Device Lett. 29, 668 (2008).

${ }^{4}$ X.-D. Wang, W.-D. Hu, X.-S. Chen, and W. Lu, IEEE Trans. Electron Devices 59, 1393 (2012).

${ }^{5}$ P. Lagger, M. Reiner, D. Pogany, and C. Ostermaier, IEEE Trans. Electron Devices 61, 1022 (2014)

${ }^{6}$ Y. Tang, K. Shinohara, D. Regan, A. Corrion, D. Brown, J. Wong, A. Schmitz, H. Fung, S. Kim, and M. Micovic, IEEE Electron Device Lett. 36, 549 (2015).

${ }^{7}$ M. A. Khan, A. Bhattarai, J. N. Kuznia, and D. T. Olson, Appl. Phys. Lett. 63, 1214 (1993).

${ }^{8}$ O. Ambacher, B. Foutz, J. Smart, J. R. Shealy, N. G. Weimann, K. Chu, M. Murphy, A. J. Sierakowski, W. J. Schaff, and L. F. Eastman, J. Appl. Phys. 87, 334 (2000).

${ }^{9}$ U. K. Mishra, P. Parikh, and Y.-F. Wu, Proc. IEEE 90, 1022 (2002).
${ }^{10}$ J. P. Ibbetson, P. T. Fini, K. D. Ness, S. P. Denbaars, J. S. Speck, and U. K. Mishra, Appl. Phys. Lett. 77, 250 (2000).

${ }^{11}$ F. Qian, D. Kai, L. Y. Kun, S. Peng, and F. Qing, Chin. Phys. Lett. 30, 127302 (2013).

${ }^{12}$ A. Kumar, R. Kapoor, M. Garg, V. Kumar, and R. Singh, Nanotechnology 28, 26LT02 (2017).

${ }^{13}$ R. Vetury, N. Q. Zhang, S. Keller, and U. K. Mishra, IEEE Trans. Electron Devices 48, 560 (2001).

${ }^{14}$ M. Gassoumi, B. Grimbert, C. Gaquiere, and H. Maaref, Semiconductors 46, 382 (2012).

${ }^{15}$ T. Hashizume, S. Ootomo, and H. Hasegawa, Appl. Phys. Lett. 83, 2952 (2003).

${ }^{16}$ Y. Hori, Z. Yatabe, and T. Hashizume, J. Appl. Phys. 114, 244503 (2013).

${ }^{17}$ M. Matys, S. Kaneki, K. Nishiguchi, B. Adamowicz, and T. Hashizume, J. Appl. Phys. 122, 224504 (2017).

${ }^{18}$ S. Heikman, S. Keller, Y. Wu, J. S. Speck, S. P. DenBaars, and U. K. Mishra, J. Appl. Phys. 93, 10114 (2003).

${ }^{19}$ B. S. Eller, J. Yang, and R. J. Nemanich, J. Electron. Mater. 43, 4560 (2014).

${ }^{20}$ R. T. Tung, Phys. Rev. B 64, 205310 (2001).

${ }^{21}$ A. Rizzi, M. Kocan, J. Malindretos, A. Schildknecht, N. Teofilov, K. Thonke, and R. Sauer, Appl. Phys. A 87, 505 (2007).

${ }^{22}$ B. K. Li, M. J. Wang, K. J. Chen, and J. N. Wang, Phys. Status Solidi C 7, 1961 (2010).

${ }^{23}$ F. Schreiber, Prog. Surf. Sci. 65, 151 (2000).

${ }^{24}$ M. Jurow, A. E. Schuckman, J. D. Batteas, and C. M. Drain, Coord. Chem. Rev. 254, 2297 (2010).

${ }^{25}$ T. Aqua, H. Cohen, O. Sinai, V. Frydman, T. Bendikov, D. Krepel, O. Hod, L. Kronik, and R. Naaman, J. Phys. Chem. C 115, 24888 (2011).

${ }^{26}$ T. Schultz, R. Schlesinger, J. Niederhausen, F. Henneberger, S. Sadofev, S. Blumstengel, A. Vollmer, F. Bussolotti, J.-P. Yang, S. Kera, K. Parvez, N. Ueno, K. Mullen, and N. Koch, Phys. Rev. B 93, 125309 (2016).

${ }^{27}$ S. Bastide, R. Butruille, D. Cahen, A. Dutta, J. Libman, A. Shanzer, L. Sun, and A. Vilan, J. Phys. Chem. B 101, 2678 (1997).

${ }^{28}$ I. Borriello, G. Cantele, D. Ninno, G. Iadonisi, M. Cossi, and V. Barone, Phys. Rev. B 76, 035430 (2007).

${ }^{29}$ R. Cohen, N. Zenou, D. Cahen, and S. Yitzchaik, Chem. Phys. Lett. 279, 270 (1997).

${ }^{30}$ A. Vilan, A. Shanzer, and D. Cahen, Nature 404, 166 (2000).

${ }^{31}$ Y. Selzer and D. Cahen, Adv. Mater. 13, 508 (2001).

${ }^{32}$ H. Haick, M. Ambrico, T. Ligonzo, and D. Cahen, Adv. Mater. 16, 2145 (2004).

${ }^{33}$ M. Garg, T. R. Naik, C. S. Pathak, V. R. Rao, and R. Singh, Appl. Phys. Lett. 112, 163502 (2018).

${ }^{34}$ M. A. Khaderbad, R. Pandharipande, V. Singh, S. Madhu, M. Ravikanth, and V. R. Rao, IEEE Trans. Electron Devices 59, 1963 (2012).

${ }^{35}$ M. A. Khaderbad, V. Tjoa, M. Rao, R. Phandripande, S. Madhu, J. Wei, M. Ravikanth, N. Mathews, S. G. Mhaisalkar, and V. R. Rao, ACS Appl. Mater. Interfaces 4, 1434 (2012).

${ }^{36}$ B. Baur, J. Howgate, H.-G. von Ribbeck, Y. Gawlina, V. Bandalo, G. Steinhoff, M. Stutzmann, and M. Eickhoff, Appl. Phys. Lett. 89, 183901 (2006).

${ }^{37}$ B. S. Kang, H. T. Wang, F. Ren, and S. J. Pearton, J. Appl. Phys. 104, 031101 (2008).

${ }^{38}$ M. A. Khaderbad, U. Roy, M. Yedukondalu, M. Rajesh, M. Ravikanth, and V. R. Rao, IEEE Trans. Nanotechnol. 9, 335 (2010).

${ }^{39}$ L. Rosenberger, R. Baird, E. McCullen, G. Aunerc, and G. Shreve, Surf. Interface Anal. 40, 1254 (2008).

${ }^{40}$ J. A. Rotole and P. M. A. Sherwood, Surf. Sci. Spectra 5, 32 (1998).

${ }^{41}$ Y.-J. Lin, H.-Y. Lee, F.-T. Hwang, and C.-T. Lee, J. Electron. Mater. 30, 532 (2001).

${ }^{42}$ X. Zhang and S. Ptasinska, Sci. Rep. 6, 24848 (2016).

${ }^{43}$ V. Matolín, S. Fabík, J. Glosík, L. Bideux, Y. Ould-Metidji, and B. Gruzza, Vacuum 76, 471 (2004).

${ }^{44}$ D. K. Lavallee, J. Brace, and N. Winograd, Inorg. Chem. 18, 1776 (1979).

${ }^{45}$ G. Moldovan, I. Harrison, M. Roe, and P. D. Brown, in Presented at The Electron microscopy and analysis 2003: Proceedings of the Institute of Physics Electron Microscopy and Analysis Group Conference (University of Oxford, 2003), September, p. 115.

${ }^{46}$ S. J. Kerber, J. J. Bruckner, K. Wozniak, S. Seal, S. Hardcastle, and T. L. Barr, J. Vac. Sci. Technol. A 14, 1314 (1996).

${ }^{47}$ L. Chen, Z. Xu, J. Li, Y. Li, M. Shan, C. Wang, Z. Wang, Q. Guo, L. Liu, G. Chen, and X. Qian, J. Mater. Chem. 22, 13460 (2012).

${ }^{48}$ X. Zhang and S. Ptasinska, Phys. Chem. Chem. Phys. 17, 3909 (2015). 
${ }^{49}$ A. Vilan, J. Ghabboun, and D. Cahen, J. Phys. Chem. B 107, 6360 (2003). ${ }^{50}$ T. Ishizaki, N. Saito, L. SunHyung, K. Ishida, and O. Takai, Langmuir 22, 9962 (2006).

${ }^{51}$ P. K. B. Palomaki, A. Krawicz, and P. H. Dinolfo, Langmuir 27, 4613 (2011).

${ }^{52}$ R. M. A. Azzam, and N. M. Bashara, (North-Holland Publishing Co, New York, 1977).

${ }^{53}$ A. Kumar, S. Vinayak, and R. Singh, Curr. Appl. Phys. 13, 1137 (2013).

${ }^{54}$ W. Melitz, J. Shen, A. C. Kummel, and S. Lee, Surf. Sci. Rep. 66, 1 (2011).

${ }^{55}$ S. Hudlet, M. S. Jean, B. Roulet, J. Berger, and C. Guthmann, J. Appl. Phys. 77, 3308 (1995).

${ }^{56}$ E. H. Rhoderick, IEE Proc. I Solid State Electron Devices 129, 1 (1982).

${ }^{57}$ X. Wang, H. Liu, C. Fei, L. Zhao, S. Chen, and S. Wang, AIP Adv. 6, 065224 (2016).
${ }^{58}$ O. Ambacher, J. Smart, J. R. Shealy, N. G. Weimann, K. Chu, M. Murphy, W. J. Schaff, L. F. Eastman, R. Dimitrov, L. Wittmer, M. Stutzmann, W. Rieger, and J. Hilsenbeck, J. Appl. Phys. 85, 3222 (1999).

${ }^{59}$ H. X. Guang, Z. D. Gang, and J. D. Sheng, Chin. Phys. B 24, 067301 (2015).

${ }^{60}$ A. Kumar, T. Singh, M. Kumar, and R. Singh, Curr. Appl. Phys. 14, 491 (2014).

${ }^{61}$ L. E. Black, "New Perspectives on Surface Passivation: Understanding the $\mathrm{Si}-\mathrm{Al}_{2} \mathrm{O}_{3}$ Interface" (Springer International Publishing, Cham, 2016), p. 15.

${ }^{62}$ Z. Lin and W. Lu, J. Appl. Phys. 99, 014504 (2006).

${ }^{63}$ A. Natan, L. Kronik, H. Haick, and R. T. Tung, Adv. Mater. 19, 4103 (2007).

${ }^{64}$ G. Ashkenasy, D. Cahen, R. Cohen, A. Shanzer, and A. Vilan, Acc. Chem. Res. 35, 121 (2002).

${ }^{65}$ L. Shen, X. Cheng, Z. Wang, C. Xia, D. Cao, L. Cheng, Q. Wang, and Y. Yu, RSC Adv. 5, 86593 (2015). 